\title{
CREATIVIDAD: \\ HERRAMIENTA \\ DIDÁCTICA PARA LOS \\ DOCENTES
}

\author{
CREATIVITY: TEACHING TOOLS FOR \\ TEACHERS
}

Paulina Marisol Camargo Zamata

\section{RESUMEN}

La creatividad como estrategia didáctica es primordial en todo trabajo del docente. Constituye una de las manifestaciones más originales del ser humano, esto implica la integración de procesos cognitivos básicos y de procesos cognitivos superiores para el logro de nuevas ideas; es decir, es la capacidad de analizar, valorar y resolver diversas situaciones que se presentan en el transcurso de la vida del ser humano.

\section{PALABRAS CLAVE}

Estrategia didáctica, creatividad, pensamiento convergente, pensamiento divergente.

\section{ABSTRACT}

Creativity as a teaching strategy it is essential in all teaching work. It is one of the most original manifestations of the human being, this implies the integration of basic cognitive processes and higher cognitive processes for the achievement of new ideas, that is, the ability to analyze, assess and solve different situations that are show in the life of human being.

\section{KEYWORDS}

Teaching strategy, creativity, convergent thinking, divergent thinking.
A ctualmente la pedagogía avanza, en nuestro contexto geográfico, de forma lenta, pero con el compromiso gubernamental de mejorarla no sólo en infraestructura, sino, a través de la capacitación de los maestros, en aspectos metodológicos que los sitúe en un nivel altamente competitivo.

Tradicionalmente se relaciona educación con contenidos que se deben memorizar, aprender y explicar. No todas las escuelas miran con beneplácito la integración holística y el desarrollo de la creatividad como norte que guíe sus labores como docentes de esta nueva generación, docente mediador y generador de nuevos aprendizajes aplicando la creatividad.

Es así como la motivación y el impulso a ser creativos poco a poco está tomando posición en los colegios y universidades por cuanto se les valora más que a la simple repetición de contenidos. Crear para aprender, es la consigna que se propone por cuanto al verse estimulada, desarrolla otras habilidades para la creación y favorece la enseñanza volviéndola más lúdica y significativa.

La creatividad constituye una de las manifestaciones más originales del ser humano, esto implica la integración de procesos cognitivos básicos y de procesos cognitivos superiores para el logro de nuevas ideas; es decir, es la capacidad de analizar, valorar y resolver diversas situaciones que se presentan en el transcurso de la 
vida del ser humano. Por lo tanto, la creatividad es necesaria en toda nuestra vida cotidiana. Al respecto, Guilford, J. P. (1977) señala:

"Entre las características de la conducta creativa se encuentran: la originalidad, la flexibilidad de adaptación, la afluencia de ideas, las expresiones $y$ asociaciones de vocablos, la sensibilidad a los problemas, la visualización, el juicio y la redefinición. Considera que la creatividad es el pensamiento divergente, que es la capacidad de transposición y la flexibilidad espontánea, la capacidad para nuevas formulaciones del pensamiento y ante todo la sensibilidad ante los problemas".

Podríamos decir que Guilford, con respecto a la creatividad, nos dice que el descubrimiento del problema, es tan importante como el hallazgo de las soluciones, la búsqueda y el descubrimiento del mismo; según el autor, son aspectos que distinguen al pensamiento creador en la búsqueda de una solución.

Guilford también nos grafica claramente como el pensamiento divergente es un factor cognitivo, presentando su modelo del intelecto E. I, afirmando que estos factores son una producción creadora basándose en el desarrollo de las habilidades del pensamiento representando en un cubo de tres dimensiones: operaciones mentales, contenidos y productos, presentando el siguiente gráfico:

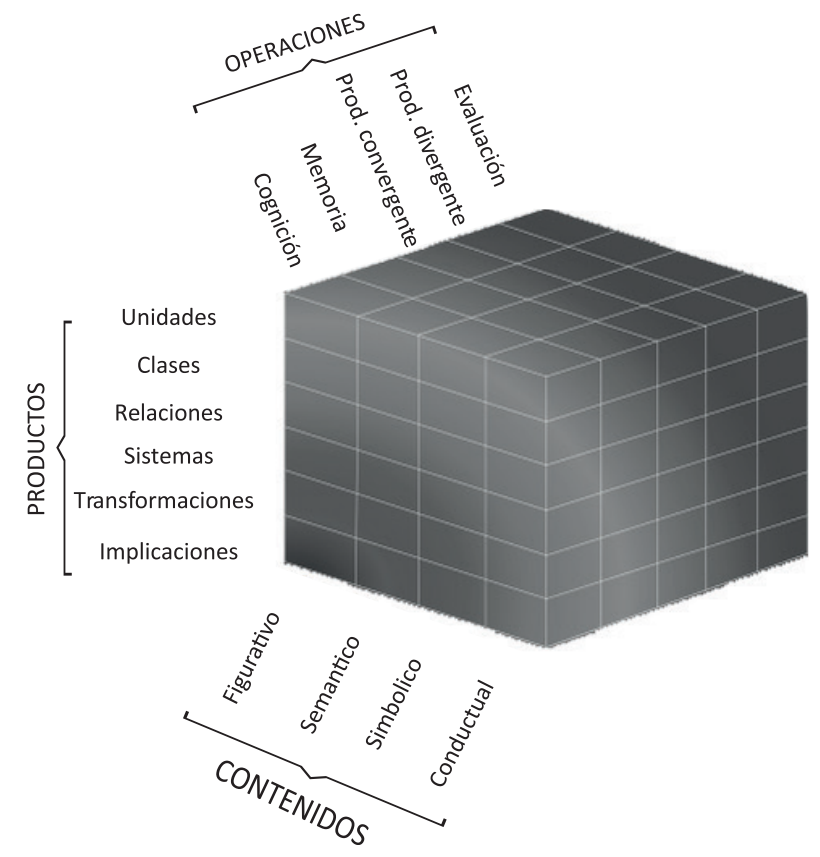

Las operaciones mentales serían el proceso intelectual que el organismo realiza con la información que recibe y que el individuo es capaz de realizar sobre la base de unos determinados contenidos informativos, dando como resultado productos mentales o formas de como expresa la persona a partir de las informaciones procesadas por las distintas operaciones dando como resultado una solución creativa al problema.

Por otro lado, analizando a Esquivas (1997), comenta que la creatividad es un proceso mental, complejo, el cual supone: actitudes, experiencias, originalidad y juego, para lograr una producción o aportación diferente a lo que ya existía.

De la Torre (1999), nos comparte que la creatividad es rodear un campo de ideas con una valla de palabras, creatividad sería como un océano de ideas desbordado por un continente de palabras. Gardner (1999), propone que la creatividad no es una especie de fluido que pueda tomar cualquier dirección. Al respecto, nos dice:

"La vida de la mente se divide en diferentes regiones, que yo denomino 'inteligencias', como la matemática, el lenguaje o la música. $Y$ una determinada persona puede ser muy original e inventiva, incluso iconoclásticamente imaginativa, en una de esas áreas sin ser particularmente creativa en ninguna de las demás”.

Según la experiencia educativa, la creatividad puede ser considerada una forma de solucionar problemas, mediante intuiciones o una combinación de ideas de campos muy diferentes de conocimientos.

Ausubel (1963), refuerza e implementa afirmando que la personalidad creadora es aquella que distingue a un individuo por la calidad y originalidad fuera de lo común de sus aportaciones a la ciencia, el arte, a la política, etcétera. Aquí Bruner (1963), completa la idea y aporta que la creatividad es un acto que produce sorpresas al sujeto, en el sentido de que no lo reconoce como producción anterior. 
Al respecto, Piaget (1964) nos dice:

"La creatividad constituye la forma final del juego simbólico de los niños, cuando éste es asimilado en su pensamiento".

Penagos (2000), propone estudiar el concepto de Creatividad desde diferentes perspectivas; así, se ha considerado como una característica de la persona, como un proceso, como parte de un contexto, pero la más generalizada, es la que la ha considerado como sinónimo de una capacidad extraordinaria de resolución de problemas. Entendiendo como problema, una circunstancia en la que se intenta conseguir el resultado y encontrar los recursos para lograrlo.

Es probable que para resolver un problema se tenga que hacer una adecuada representación de éste. La representación de un problema consiste esencialmente en la interpretación o comprensión del mismo y lo que realiza la persona que tiene que resolverlo.

Aquí cabe destacar que creatividad y solución de problemas no son sinónimas. La sola visión de un problema ya es un acto creativo. En cambio, su solución puede ser producto de habilidades técnicas. El darse cuenta del problema significa integrar, ver, asociar, donde otros no han visto, es decir, un estado de conciencia diferente. En este acto de darse cuenta, intervienen componentes actitudinales, sociales, afectivos, además de procesos fisiológicos.

Csikszentmihalyi (1995), desde una perspectiva integradora, explica la creatividad como una función de tres elementos: campo (disciplina, o lugar en donde ocurre la creatividad), dominio (grupo social de expertos) y persona (quien realiza el acto creativo). Estas dos últimas aproximaciones hacia la comprensión de la creatividad destacan por intentar una construcción más global del fenómeno creativo.

Por otro lado, Amabile (1983) afirma que la creatividad existe en tanto existan: destrezas en el campo, destrezas para la creatividad y características específicas de motivación a la tarea; el autor sugiere la necesidad de destrezas y conocimientos propios del campo en que se desempeña la persona creativa; es decir, para ser creativo en música se tiene que conocer algo de música, poseer las habilidades técnicas necesarias y un "talento" especial. No necesariamente se habla aquí de una educación formal, sino de conocimiento en el sentido más amplio de la palabra. Las destrezas en el campo son favorecidas por la educación formal y no individuales. Además de las destrezas en el campo, se requieren de destrezas propias para la creatividad como puede ser pensamiento flexible y capacidad heurística. Finalmente, es necesaria una alta motivación intrínseca, así como tenacidad y capacidad para reducir las presiones extrínsecas, coincide con Csikszentmihalyi (1988), quien considera que:

"La fuerza motivacional, si bien no es una condición suficiente para la creatividad, parece ser un factor importante".

Los modelos de ambos autores mencionados se complementan, consideran el campo como un factor sustancial, ambos ven la necesidad de características propias de la persona creativa.

Si bien es cierto que el dominio es un factor de primer orden en la creatividad, también es cierto que cuando ocurren eventos altamente creativos, estos dominios cambian e incluso ocurren transformaciones radicales en el campo, generándose un nuevo orden de actividades y de productos creativos. Ahora bien, Boden (1991), nos comenta que hay una creatividad-h y una creatividad-p, es decir una creatividad histórica y una creatividad personal. En un sentido similar, Gardner (1995) afirma que la creatividad requiere de cuatro niveles de análisis: a) subpersonal (sustrato biológico), b) personal (sustrato psicológico), c) impersonal (el campo), y d) multipersonal. Ha estudiado la creatividad con un enfoque similar al de su teoría de las inteligencias múltiples. De lo que se puede sugerir que también existen diferentes tipos de creatividad, relacionados a los diferentes tipos de inteligencia. 
En las diferentes definiciones de creatividad, se proponen tipos y niveles; sin embargo, podemos decir que en todos ellos hay algo que les es característico y que los define como creatividad: "La creatividad es un dominio del conocimiento, que permite a la persona generar una red de relaciones para identificar, plantear y resolver problemas de manera relevante y divergente".

Cabe destacar que la escuela tendría como intención última formar a sus estudiantes con capacidad de pensar y crear ante las cotidianidades que enfrentan, soluciones creativas ante un problema que se le presente. Entender que la escuela es un espacio activo, lúdico, que promueva las situaciones de enseñanza-aprendizaje utilizando el pensamiento divergente, tanto del profesor como del alumno en las diversas actividades o diversas sesiones de aprendizaje. Ante esto, Ballester señala:

"Las situaciones abiertas de aprendizaje, a partir de experiencias y emociones personales, con estímulo del pensamiento divergente en que el alumnado proyecta sus ideas, potencian la diferencia individual y la originalidad y se convierten en hechos claves y decisivos para una enseñanza activa y creativa”.

Podemos concluir que la creatividad como estrategia didáctica es primordial en todo trabajo del docente, apoyándonos en el pensamiento divergente; logrando desarrollar este pensamiento en nuestros estudiantes, en la búsqueda de solución a un problema y puesta en práctica en la vida cotidiana. 


\section{REFERENCIAS}

Aranda, E. (1991). Manual de la creatividad: Aplicaciones Educativas. Barcelona: Vicens Vives.

Ballester, Vallri, A. (2002). El aprendizaje significativo en la práctica. Cómo hacer el aprendizaje significativo en el aula. España: Edit. Paidos.

Beltrán, J.; Bueno, J. A. (1995). Psicología de la Educación. Edit. Baixaren Universitaria.

Camargo Zamata, P. M. (2017). Aplicación de estrategias didácticas innovadoras para el desarrollo del pensamiento creativo en las estudiantes universitarias de una universidad de Lima. Tesis para optar el grado de magíster en educación con mención en teorías y práctica educativa. Universidad de Piura - UDEP.

Csikszentmihalyi, M. (1995). Creatividad una aproximación. México.

Díaz Andrade, J. (2013). ¿Qué estrategias de enseñanza y aprendizaje fomentan el desarrollo de la capacidad creativa en estudiantes de preparatoria presencial en el aprendizaje efectivo en el área de ciencias sociales? Revista Iberoamericana para la investigación y el desarrollo educativo, 6(3), 237-267.

De la Torre, S. (1999). Educar en la creatividad: recursos para el medio escolar. Madrid: Narcea.
Espriú, R. (2005). El niño y la creatividad. México, D. F.: Editorial Trillas.

Esquivas, S. M. T. (2001). Propuesta para el desarrollo de la "Creatividad" en Educación Superior: Estudio comparativo entre dos universidades mexicanas. Universidad Anáhuac. Facultad de Educación. Tesis de Maestría.

Gardner, H. (1999). Estructuras de la mente. La teoría de las inteligencias múltiples. Colombia: Fondo de Cultura Económica.

Gardner, H. Research Projects. http://www. pz.harvard.edu/Research/Research.htm Consulta: 25 de septiembre de 2003.

Guilford, J. P. (1977). Psicología General. México: Diana.

Hinojosa, M. (2010). Pensamiento creativo. México: Trillas.

Kelley, T. y Kelley, D. (2013). Creative Confidence: Unleashing the creative potential within us all. San Francisco, Estados Unidos: Crow Pub Inc.

Piaget, J. (1965). Psicología de la Inteligencia. Buenos Aires: Psique.

Rojas Morote, Nori (2000). Arte y creatividad. Expresión Plástica. Perú: San Marcos.

Sánchez, C. (1995). Inteligencia y Creatividad. Perú: Psicopedagogía.

Villegas Fernández, B. (2008). Estrategias docentes en el desarrollo de la creatividad escolar. REDHECS, 5(3),65-76. 